\title{
La formación en valores a través de la religión en la primera infância
}

\section{Values formation through religion in early childhood}

DOI: $10.46932 / \mathrm{sfjdv2n5-064}$

Received in: Oct 1st, 2021

Accepted in: Dec 30th, 2021

\author{
María Del Carmen Vivero Riquelme \\ Grado En Educación Infantil Y Primaria \\ Calle Gabriel García Márquez, 3. 30508, Murcia. \\ E-mail: Investigacionrgformacion@gmail.com
}

\section{RESUMEN}

Este trabajo surge con el objetivo de facilitar una educación integral a los niños durante sus primeros años, fortaleciendo su desarrollo personal y social mediante un conjunto de actividades lúdicas centradas en la importancia de celebrar la Eucaristía. Con este plan, también aspiramos a buscar puntos de unión entre la Eucaristía y la formación espiritual en la escuela, de manera que sirva para avivar la fe de los niños alrededor de los valores de referencia cistianos. La propuesta didáctica propuesta, además de proporcionar diversión y nuevos conocimientos, beneficiarán la individualización y estimularán las destrezas sociales de los alumnos. Al tratarse de sesiones simples, que no requieren de una gran implicación por parte del profesorado, pueden resultar muy útiles para ellos. El soporte en una parábola de las Sagradas Escrituras nos ayudará para comunicar las enseñanzas de Jesús a nuestros alumnos y adaptar los valores a nuestra vida cotidiana.

Palabras clave: Eucaristía, Iglesia, Jesús, religión, alumnos, professor.

\begin{abstract}
This work arises with the objective of facilitating an integral education to children during their early years, strengthening their personal and social development through a set of playful activities centered on the importance of celebrating the Eucharist. With this plan, we also aspire to seek points of union between the Eucharist and spiritual formation in the school, so that it serves to enliven the faith of the children around the values of Christian reference. The proposed didactic proposal, besides providing fun and new knowledge, will benefit the individualization and stimulate the social skills of the students. As these are simple sessions, which do not require a great involvement of the teachers, they can be very useful for them. The support in a parable from the Holy Scriptures will help us to communicate the teachings of Jesus to our students and to adapt the values to our daily life.
\end{abstract}

Keywords: Eucharist, Church, Jesus, religion, students, teacher.

\section{INTRODUCCIÓN}

Este artículo es fruto de dar respuestas a las diferentes preguntas que se manifiestan en los niños acerca de Jesús, temas que pretendemos abordar a través de una educación basada en el amor y en la unión existente con Dios. La cuestión central en torno a la que gira este artículo es la siguiente: 
- ¿Qué es el sacramento de la Eucaristía?

Con la transmisión del ejemplo de amor en el que Jesús de Nazaret convirtió su vida, esperamos que los niños descubran la importancia de la fe en Cristo. El establecimiento de este vínculo tiene su culmen en la celebración de la Eucaristía, sacramento fundamental para conocer a Jesús y percibir su amor en nuestros corazones. Los católicos entendemos la Eucaristía como la celebración más importante de nuestra fe, destacando la consagración como el momento en el que se actualiza la Última Cena.

La autenticidad característica de los más pequeños puede fortalecerse en este vínculo con Jesús, proporcionándoles una presencia a la que pueden recurrir siempre. Para ello, hay que hacerles sentir apóstoles de la Eucaristía, encargados de poner en práctica el mensaje de Jesús en el mundo.

Actualmente, la clase de religión se puede reducir a un diálogo entre el maestro y el alumnado para comprender el mundo desde la visión cristiana. En ella, se trata la contribución del cristianismo en la cultura, el arte, la ciencia o la historia. Por ello, este trabajo está orientado a organizar una propuesta de intervención transversal que ofrezca elementos que favorezcan la dinámica educativa de la exposición catequética al profesorado.

Este proyecto innovador e interdisciplinar incluye un conjunto de actividades que permitirán al maestro evaluar y analizar la evolución de los alumnos a lo largo del curso-etapa. Está basado en construir bases cognitivas y afectivas en los niños, favoreciendo el aprendizaje significativo de los contenidos.

\section{LA EUCARISTÍA}

El número 1323 del Catecismo de la Iglesia Católica, describe el sacramento de la Eucaristía de la siguiente manera:

“Nuestro Salvador, en la última Cena, la noche en que fue entregado, instituyó el Sacrificio Eucarístico de su cuerpo y su sangre para perpetuar por los siglos, hasta su vuelta, el sacrificio de la cruz y confiar así a su Esposa amada, la Iglesia, el memorial de su muerte y resurrección, sacramento de piedad, signo de unidad, vínculo de amor, banquete pascual en el que se recibe a Cristo, el alma se llena de gracia y se nos da una prenda de la gloria futura'.

Por su parte, la constitución Sacrosanctum Concilium afirma que por medio de la sagrada liturgia "se ejerce la obra de nuestra Redención", contribuyendo en sumo grado a que los fieles expresen en su vida, y manifiesten a los demás, el misterio de Cristo y la naturaleza auténtica de la verdadera Iglesia.

Diversos autores, como Aldazábal (1999), estudian la relación de la Eucaristía con el Espíritu Santo, la Eucaristía como acontecimiento y memorial, como actualización de la Iniciación Cristiana, como sacramento de salvación escatológica, como manifestación principal de la Iglesia y razón por la que se edifica. 


\section{1 ¿QUÉ ES EL SACRAMENTO DE LA EUCARISTÍA?}

El Concilio Vaticano II, en su Constitución Sacrosanctum Concilium (1963), se definió la

La Eucaristía como "fuente y culmen de toda la vida cristiana";. Por su parte, en el decreto sobre el ministerio y la vida de los sacerdotes promulgado por el Papa Pablo VI (1965), Presbyterorum Ordinis añade que la Eucaristía "contiene todo el bien espiritual de la Iglesia, es decir Cristo mismo, nuestra Pascua". Por lo tanto, entendemos la Eucaristía como unión central de sacramentos, ministerios eclesiales y obras de apostolado.

Apoyándonos en los contenidos de la Biblia, en el siguiente discurso de Jesús en la sinagoga de Cafarnaún, presente en los evangelios de San Juan, se aprecia la importancia de la Eucaristía: "Yo soy el pan vivo que ha bajado del cielo. Quien come de este pan, vivirá eternamente, y el pan que yo daré es mi misma carne para la vida del mundo" (Juan 6, 51-52). Dicho evangelio es una muestra de la importancia de la Eucaristía en el acercamiento a la fe en Dios: "Yo soy el pan de vida; el que viene a mí ya no tendrá más hambre y el que cree en mí ya nunca tendrá sed" (Juan 6, 35).

La institución de la Eucaristía también se aprecia en los evangelios de Mateo (26, 26-28): "Mientras estaban comiendo, tomó Jesús el pan y lo bendijo, lo partió y dándoselo a sus discípulos, dijo: “Tomad y comed, porque éste es mi cuerpo, que será entregado por vosotros; haced esto en memoria mía”. Tomando después una copa dio gracias y la bendijo diciendo: "Tomad y bebed todos, porque este es el cáliz de la nueva alianza en mi sangre, que será derramada por vosotros”.

Según las palabras de Santa Teresa del Niño Jesús, en la Historia de un Alma, el sacramento de la Eucaristía es un sentimiento espiritual que consolida el alma, a la par es el Sacramento de la unidad, que agrupa a todos los fieles cristianos para conmemorar el triunfo de Jesús resucitado en la Eucaristía, sin dejar la comunión con los hermanos sino más bien permanecer en el Amor. (2019)

El sacerdote y fraile Pío de Pietrelcina (1887-1968), conocido por sus grandes milagros y por la presencia de estigmas en sus manos y en sus pies al igual que Cristo, afirmó que "la Eucaristía es el mayor de todos los milagros. Es el signo más grande del amor de Jesús por nosotros. Él ha hecho todo esto para darnos una vida eterna, abundante, perfecta”.

\subsection{PARTES DE LA EUCARISTÍA}

\subsubsection{La misa de los niños}

La Misa es una ceremonia en la que se hace presente la muerte de Cristo para purificar nuestros pecados. Jesús sigue dando su vida por nosotros en la cruz. Por eso, la Misa es una gran celebración para los católicos, esta ceremonia se debe a la resurrección de Jesús. Asimismo, Jesús fundó la Eucaristía con 
motivo de la festividad de la Pascua para los judíos, de esta forma podemos comprender que la Eucaristía es la gran fiesta de los cristianos, la cual sustituye a la Pascua judía.

San Juan Bautista María Vianney (1786-1859), exponía: La santa misa alegra toda la corte celestial, alivia a las pobres almas del purgatorio, atrae sobre la tierra toda suerte de bendiciones y da más gloria a Dios que todos los sufrimientos de los mártires juntos, que las penitencias de todos los solitarios, que todas las lágrimas por ellos derramadas desde el principio del mundo y que todo lo que hagan hasta el fin de los siglos. Al igual que hemos visto en la anterior definición la misa es la representación de Dios en la Tierra, es el acto cotidiano más importante y común para la Iglesia Católica, donde celebramos la Eucaristía, el sacramento de nuestra fe, en ella, se rememora la muerte de Jesús y recuerda a los fieles su resurrección.

Según la Sagrada Congregación para el culto divino (1973) explica que existe una particular dificultad para la educación de los niños en la Iglesia, por el hecho de que las celebraciones litúrgicas, especialmente las eucaristías, no pueden ejercer plenamente sobre ellos la fuerza pedagógica que le es propia. A pesar del empleo autorizado actualmente de la lengua vernácula, las palabras y los signos no se adecuan lo suficiente a la capacidad de los niños. De esta manera proponemos un proyecto novedoso, adaptándonos a las características de cada uno de nuestros alumnos, a su edad, a sus necesidades individuales, para motivarlos y ayudarlos a conocer más profundamente el tema tratado.

A los niños, es fundamental que desde bien pequeños aprendan a amar a Jesús en la Eucaristía e invitarlos a que participen en ella, para que su amor hacia Jesús no se pierda, sino que poco a poco vaya creciendo.

\subsection{PARÁBOLAS OTROS RELATOS EVANGÉLICOS}

La REAL ACADEMIA ESPAÑOLA define parábola como, 'Narración de un suceso fingido, que se deduce, por comparación o semejanza, una verdad importante o una enseñanza moral. Entre otras definiciones, la palabra parábola designa un relato ficticio que, por comparación con la realidad, se deriva una enseñanza moral o un mejor conocimiento de la verdad.

Otra de las definiciones del término parábola la encontramos en la enciclopedia Planeta Saber expone que son una alegoría que sirve para explicar una verdad, una enseñanza: Las parábolas del Evangelio son una comparación, utilizada por Jesucristo en su predicación para introducir el auditorio paulatinamente en su doctrina. Estas enseñanzas se les puede transmitir a los pequeños en forma de cuento con un lenguaje adecuado para ellos, así comprenderán con mayor facilidad todo lo que Jesús quiso comunicarnos. 
El término parábola proviene del griego parabole, el nombre dado por los retóricos griegos a toda ilustración ficticia en la forma de una breve narrativa. Más adelante pasó a conocerse como narrativa ficticia, aludiendo generalmente a algo que puede ocurrir de forma natural, y por el cual se precisan asuntos morales y espirituales, (Fyler,1887:37)

Las parábolas extraídas de la Biblia son referentes religiosos, aportan una gran cantidad de beneficios, siendo un instrumento útil para la enseñanza de valores, confortar la autonomía e identidad, mejorar la relación con nuestros iguales, y gracias a las enseñanzas que estos textos abarcan por el tipo de contenido ayudan a fortalecer nuestra autoestima.

Tal y como afirma Ricoeur (2013), "Las parábolas son relatos ordinarios en los que toda la potencia metafórica está concentrada en un momento de crisis y en un desenlace trágico o cómico". Este recurso incluido en nuestra propuesta de intervención, resulta ser un útil instrumento en el aula. Podemos explicar las parábolas siguiendo la estructura de un cuento (inicio, nudo y desenlace), de esta manera captamos la atención de los más pequeños. Con la finalidad de cumplir con el propósito literario y complacer el deseo del lector.

\subsubsection{El Banquete Nupcial del Gran banquete nupcial o del Matrimonio del Rey}

A continuación, analizaremos la parábola narrada por Jesús en el Nuevo Testamento:

Jesús les habló otra vez en parábolas, diciendo: «El Reino de los Cielos se parece a un rey que celebraba las bodas de su hijo. Envió entonces a sus servidores para avisar a los invitados, pero estos se negaron a ir. De nuevo envió a otros servidores con el encargo de decir a los invitados: "Mi banquete está preparado; ya han sido matados mis terneros y mis mejores animales, y todo está a punto: Vengan a las bodas". Pero ellos no tuvieron en cuenta la invitación, y se fueron, uno a su campo, otro a su negocio; y los demás se apoderaron de los servidores, los maltrataron y los mataron. Al enterarse, el rey se indignó y envió a sus tropas para que acabaran con aquellos homicidas e incendiaran su ciudad. Luego dijo a sus servidores: "El banquete nupcial está preparado, pero los invitados no eran dignos de él. Salgan a los cruces de los caminos e inviten a todos los que encuentren”. Los servidores salieron a los caminos y reunieron a todos los que encontraron, buenos y malos, y la sala nupcial se llenó de convidados. Cuando el rey entró para ver a los comensales, encontró a un hombre que no tenía el traje de fiesta. “Amigo, le dijo, ¿cómo has entrado aquí sin el traje de fiesta?”. El otro permaneció en silencio. Entonces el rey dijo a los guardias: "Atenlo de pies y manos, y arrójenlo afuera, a las tinieblas. Allí habrá llanto y rechinar de dientes”. Porque muchos son llamados, pero pocos son elegidos». (Mt 22,3-14) 
Esta parábola la podemos asemejar a la bienvenida que ofrece Jesús a todo el mundo en la Iglesia, donde reúne gente de todas partes, buenos, malos, pobres, abandonados, sin ninguna distinción con el fin de ofrecer su amor y enseñanzas a cuantos quieran.

Además, de las parábolas también en este trabajo haremos un breve recorrido de los diversos relatos evangélicos, donde gracias a ellos podemos entender la institución de la Eucaristía.

\subsubsection{La multiplicación de los panes y de los peces}

En aquel tiempo, vio Jesús una gran multitud y tuvo compasión de ellos, porque eran como ovejas que no tienen pastor, y comenzó a enseñarles muchas cosas. Y como fuese muy tarde, llegaron a Él sus discípulos y le dijeron: «Este lugar es desierto y la hora es ya pasada; despídelos para que vayan a las granjas y aldeas de la comarca a comprar de comer». Y Él les respondió y dijo: «Dadles vosotros de comer». Y le dijeron: «¿Es que vamos a comprar doscientos denarios de pan para darles de comer?». Él les contestó: «¿Cuántos panes tenéis? Id a verlo». Y habiéndolo visto, dicen:«Cinco, y dos peces».

Entonces les mandó que se acomodaran todos por grupos de comensales sobre la hierba verde. Y se sentaron en grupos de ciento y de cincuenta. Y tomando los cinco panes y los dos peces y levantando los ojos al cielo, bendijo, partió los panes y los dio a sus discípulos para que los distribuyesen; también partió los dos peces para todos. Y comieron todos hasta que quedaron satisfechos. Y recogieron doce cestas llenas de los trozos que sobraron de los panes y de los peces. Los que comieron eran cinco mil hombres. (Mc 6,34-44)

Después de analizar este relato bíblico de la multiplicación de los panes y de los peces observamos un antecedente de la Santa Misa actual en el momento de la consagración donde el sacerdote, en nombre de Dios, nos invita a tomar el Cuerpo y Sangre de Cristo, donde todos somos dignos de participar en la celebración de este gran Milagro Eucarístico que nos acerca a nuestro padre celestial.

- Como se afirma en Infovaticana (2014): 'Al terminar la comida, los discípulos guardan las sobras de panes y peces: es un símbolo de la reserva en el Sagrario tras la Santa Misa'.

\section{EDUCACIÓN EN VALORES}

Como hemos avanzado, la asignatura de Religión contribuye al desarrollo de la educación en valores. Según Marín y Sánchez, “educar es hacer que el educando ponga los valores en su vida, que los conozca, los aproveche, los estime y los haga crecer" (2015, p. 1096). Esta forma de enseñar, tan a largo plazo en la edad infantil, resulta tarea difícil para unos maestros que deberán transmitir con paciencia los mensajes oportunos para contribuir de manera positiva a la educación y crecimiento de los alumnos. 
Dentro de este tipo de educación destaca la figura del profesor. Según Touriñan (2006), la labor de un maestro a la hora de la enseñanza de valores no trata de someter al educando a aprendizajes sobre los saberes, sino que el niño debe descubrir y experimentar que le proporcionan esos conocimientos. Es decir, para que un alumno adquiera un valor debe comenzar comprobando los buenos resultados que les aporta esa conducta.

Tras un breve acercamiento a diversas definiciones sobre la educación en valores, sus principales características y su relación con el ámbito educativo, resulta importante conocer la importancia que tiene el juego a lo largo de este proyecto.

El juego es una destreza presente en todos los individuos. Aunque mantiene un fuerte vínculo con el ámbito infantil, dicha actividad puede ocurrir en cualquier momento de la vida ( Chamorro,2010).

Una concepción general sobre el juego la encontramos en Baena y Ruiz (2016), que dicen que ayuda a pulir aspectos de la personalidad del alumno. También le permite adquirir aprendizajes comunicativos, físicos y motores, facilitando la aparición de experiencias que favorecen al infante a la hora de desenvolverse en el mundo que le rodea.

Como afirma Jaqueira et al. (2013), "los juegos cooperativos son recursos magníficos para

promover la educación de la convivencia pacífica y desencadenar emociones positivas intensas" (p.18). Esta forma de ver los juegos cooperativos ya la expuso Llopis (2003), que afirmó que su práctica favorece la obtención de valores para todo el grupo, además de fomentar la comunicación entre sus miembros, a la hora de compartir sus experiencias, y empatizar con el compañero.

Autores como Cuéllar y Pérez (2015) analizaron varios estudios en base al vínculo existente entre el juego cooperativo y el desarrollo infantil, e indicaron que el aprendizaje cooperativo propicia aprendizajes sociales en alumnos con dificultades en su desarrollo.

\section{LA CLASE DE RELIGIÓN}

Según el principio 1 de la Declaración de los Derechos del Niño (1959) “serán reconocidos a todos los niños sin excepción alguna ni distinción o discriminación por motivos de raza, color, sexo, idioma, religión, opiniones políticas o de otra índole, origen nacional o social, posición económica, nacimiento u otra condición, ya sea del propio niño o de su familia".

Asimismo, el artículo número 5 de la ONU (1981) destaca: “Todo niño gozará del derecho a tener acceso a la educación en materia de religión o convicciones conforme con los deseos de sus padres o, en su caso, sus tutores legales, y no se le obligará a instruirse en una religión o convicciones contra los deseos de tus padres o tutores legales, sirviendo de principio rector el interés superior del niño". 
Teniendo en cuenta que los alumnos tienen derecho a recibir una orientación religiosa conforme a las convicciones propias de sus padres, Martel (2007) afirma que el primer acercamiento que establecen los niños con Dios es consecuencia de las creencias de sus padres, ya que la fe de los más pequeños es por osmosis, reproducen todo lo que ven y oyen. Por lo tanto, podemos decir que la Iglesia se irá incorporando al esquema sociocognitivo del niño en la medida en que esté incorporada en la vida de la familia. Mediante esta relación, los niños aprenden a vivir con Dios, a conectar su vida con el mensaje positivo, dotándole de sentido a cada situación que experimentan.

Según la Delegación Episcopal de Enseñanza del arzobispado de Oviedo, El profesor de religión es también miembro y testigo de la Iglesia que le envía a la escuela con una misión específica: enviado. (primera parte) por la Iglesia, realiza un ministerio eclesial (segunda parte) en el que da testimonio (tercera parte), con su vida, de esa enseñanza. (2018)

Los maestros de religión son miembros de la Iglesia, han recibido el Bautismo en la misión

Evangelizadora. El docente de religión es el encargado de enseñar los valores que se aprenden en la Iglesia, para ello debe de estar preparado y con una formación adecuada.

\section{METODOLOGÍA}

En cuanto a la metodología de investigación del proyecto, partimos de un aprendizaje

significativo y constructivista, cuyo objetivo es acercar a los alumnos de Educación Primaria a la celebración de la Eucaristía mediante la comunicación y relación con los demás.

El proyecto está formado por un conjunto de actividades, adicionales a la transmisión de la enseñanza básica, donde el docente será el encargado de observar y analizar el proceso de aprendizaje de sus alumnos para, más adelante, evaluarlos. Las actividades serán dirigidas em todo momento por el maestro, sin embargo, no todo el conjunto de actividades depende de su control y orientación, debido a que se compone de juegos autónomos y dirigidos.

El maestro, que se ocupará de organizar las sesiones, anotará diariamente como van progresando sus alumnos ante el conjunto de actividades propuestas. De esta manera, obtendrá información detallada y gradual que le favorecerá la consecutiva evaluación de los educandos, notando el cambio experimentado por los infantes desde que comenzaron el proceso, estimando si han progresado su capacidad empática, las relaciones con sus compañeros, su madurez personal y, sobre todo, su grado de comprensión del significado de Eucaristía.

Las tareas incorporadas en este trabajo son grupales, pues se busca potenciar la cooperatividad y el bienestar del alumnado. Según vaya avanzando el plan, aparecerán problemas a la hora de resolver una 
actividad y, ellos mismos, estimará el modo de solucionarlo. Las actividades se realizan tanto en las aulas como en el aula de psicomotricidad.

Las agrupaciones de alumnos estarán organizadas según las conductas que los niños

manifiesten en el aula, dividiendo a los alumnos que tengan comportamientos opuestos. De esta forma, se intenta fomentar la convivencia en la clase de primaria. Un ejemplo de ello, a los infantes que no muestren una conducta apropiada en el aula se les situará con los alumnos más calmados, acostumbrados a manifestar un comportamiento positivo y educado. Esto creará un ambiente en el que los niños alimentarán sus capacidades de manera recíproca.

Además de los diferentes espacios tradicionales que encontramos en una clase de primaria, como el rincón de la lectoescritura, matemáticas, conocimiento del medio, inglés o plástica, hemos planteado la creación de un innovador rincón de religión, donde puedan participar todos los niños independientemente de sus creencias. Nos dedicaremos a la resolución de conflictos y problemas entre ellos, anunciaremos noticias o cualquier motivo de alegría, siempre contando con la presencia de Jesús. Este rincón lo denominaremos 'Escuchamos y Hablamos con Jesús'.

De esta forma, el espacio contará con dos sillas y los alumnos podrán exponer sus problemas, alegrías o peticiones durante un determinado periodo de tiempo. Ambos tendrán ocasión de transmitir su malestar y manifestar sus emociones de manera mutua. Con este fin, pretendemos enseñar a los niños a solventar sus conflictos de manera autónoma, sin que el maestro intermedie en la resolución de los problemas.

Al finalizar la realización del conjunto de actividades desarrolladas en la propuesta didáctica, el maestro expondrá una serie de preguntas a sus alumnos para percibir cómo se encuentran, si les ha motivado estas actividades, si consideran que ha mejorado la relación con Dios, si han sabido llegar al final del problema juntos, como lo han conseguido... Estas preguntas tienen el propósito de apreciar en los niños una capacidad de análisis, razonamiento y comunicación, que favorezca la comprensión de lo sucedido.

En definitiva, con este trabajo interdisciplinar que engloba una variedad de ramas de Educación Infantil, perseguimos obtener como resultado que nuestro alumnado comience a conocer, de manera independiente, su cuerpo y su mente para favorecer su capacidad reflexiva a partir de una serie de principios y estrategias metodológicas flexibles y motivadoras, que contribuyan a los alumnos a desarrollar su personalidad a través de la enseñanza de las distintas actividades lúdicas y creativas. 


\section{DISEÑO}

Para llevar a cabo nuestro programa de intervención es fundamental conocer la diversidad que presenta el alumnado, identificar aquellos alumnos con necesidades educativas especiales, altas capacidades... Es importante tener en cuenta este aspecto, ya que a raíz de este punto debemos realizar una organización del espacio adaptada a las necesidades individuales y realizar una elección de los recursos adecuados para la explicación de las actividades, programadas teniendo en cuenta los momentos del día donde los alumnos se encuentran más motivados o, por el contrario, sin interés o cansados.

El siguiente paso que tendremos en cuenta será realizar un estudio del aula, los espacios en los que impartimos las sesiones de intervención. En esta propuesta, la organización del aula será en pequeños grupos, ya que este trabajo busca la cooperatividad y el bienestar del alumnado con el fin de mejorar las relaciones entre los compañeros. El docente en todo momento tendrá la labor de animar y estimular el aprendizaje de los estudiantes.

Posteriormente, debemos conocer los recursos disponibles para poder llevar a cabo el diseño de las actividades, en este proyecto disponemos de parábolas preparadas previamente por la maestra. También, en todo momento estaremos en contacto con los padres de los estudiantes a través de la aplicación Blackboard donde podrán encontrar los materiales que hacen falta para cada actividad.

Una vez que hayamos resuelto los puntos mencionados anteriormente, realizaremos la programación del aula. Nuestra planificación nace de los objetivos e hipótesis que pretendemos que los niños alcancen con este proyecto. Dividiremos las sesiones en diferentes fases: Fase Inicial, Fase Intermedia o de Implementación y Fase Final.

En la Fase Inicial se trata de actividades donde se presenta el tema principal de este proyecto. Durante este periodo, los docentes realizarán una observación acerca de cómo se muestran los niños ante la exposición de un nuevo proyecto, anotaremos en todo momento nuestras primeras impresiones.

Fase Intermedia o de Implementación, está basada en la profundización del tema principal con la adquisición de nuevos conceptos relacionados con la Eucaristía.

Fase Final, podemos observar los cambios percibidos en los alumnos, utilizaremos esta fase de manera evaluadora para ver si los niños han comprendido el significado de la Eucaristía.

Para comprobar si nuestro trabajo como docentes o guías es óptimo y facilita el aprendizaje de los niños, realizaremos una evaluación para el alumnado, una valoración de la metodología y, por último, una autoevaluación, es decir, realizar una valoración crítica de nuestro propio trabajo.

\subsection{INSTRUMENTOS}

En este proyecto, el docente utilizará la observación directa y sistemática como técnica e 
instrumento para la recogida de información, anotando en el diario de campo aquellos aspectos reflejados en los alumnos que más le hayan llamado la atención. Se valorará la actitud de nuestros alumnos, es decir, si participan, cooperan... Algunas de las actividades diseñadas en nuestra propuesta son instrumentos basados en la formulación de preguntas (pruebas interrogativas). Un ejemplo de ello es por medio de la lectura de las parábolas, en las que presentaremos a los estudiantes una serie de cuestiones con el fin de despertar su capacidad reflexiva.

También se valorará la creatividad en las puestas en común, la cooperatividad entre los alumnos de un grupo, el diálogo con los demás alumnos y, finalmente, también se tendrá en cuenta la iniciativa de cada uno de los estudiantes.

\subsection{VARIABLES E HIPÓTESIS}

Podemos distinguir entre variables dependientes e independientes:

La variable dependiente en este caso sería la Eucaristía, ya que pretendemos comprobar si la idea que tenían los alumnos sobre este concepto mejora o, por el contrario, no comprenden su significado. Por otro lado, la variable independiente sería el programa de intervención propuesto, en el que el maestro puede realizar cambios según las consideraciones que observe a lo largo del proyecto.

En cuanto a las hipótesis que pretendemos conseguir que los niños adquieran, encontramos:

Comprobar si a través de la exposición de relatos bíblicos, actividades cooperativas y juegos lúdicos realizados en la clase de Religión, los alumnos descubren en la celebración de la Eucaristía la persona de Jesucristo.

Consideramos que esta metodología de investigación despierta la curiosidad e interés de los más pequeños, proponiendo una serie de juegos lúdicos terminados con cuestiones o frases formuladas por el profesor, que servirán como enseñanza moral para los niños. De esta manera, podrán conocer la gran labor que realizó Jesús transmitiendo enseñanzas a través de la narración de las parábolas, muy útiles para aplicar en el día a día.

También podemos conocer la doctrina cristiana a través de la Palabra de Dios, basada en una educación en valores que proporcione a los alumnos una mejora en la toma de decisiones adecuadas, sin llegar a lastimar a uno mismo ni a las personas que nos rodean, intentando mejorar la autoestima de nuestros alumnos y su carácter empático. 
Mapa Conceptual de los contenidos incluidos en nuestra propuesta de intervención.

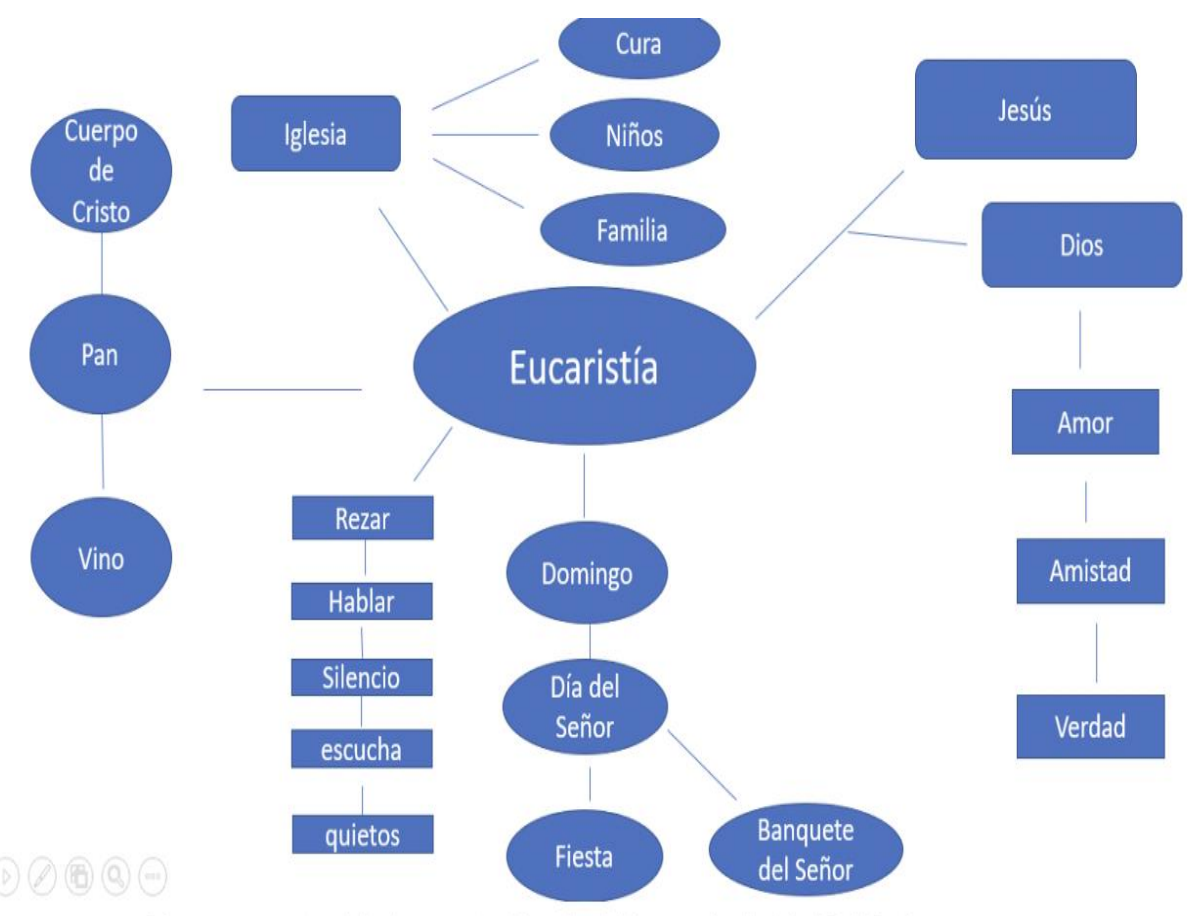

\section{ACTIVIDADES}

Como hemos explicado, realizaremos una propuesta de intervención de carácter interdisciplinar y significativo en el aula, dividida en nueve sesiones. El objetivo es que nuestros alumnos aumenten su compenetración y desarrollen los contenidos básicos de cada área, consiguiendo los conocimientos estimados y resolviendo sus interrogantes. Nuestra propuesta cuenta con una amplia variedad de juegos y recursos útiles para llevar a cabo la clase de religión. Las sesiones están divididas en 3 fases:

\subsection{FASE INICIAL}

\section{$\underline{\text { Sesión nº1. 'Parábola del banquete nupcial' }}$}

En esta sesión, queremos iniciar a los niños en el tema por excelencia de este proyecto: la Eucaristía. Para ello, contaremos a los niños la 'Parábola del banquete nupcial', también conocida como 'del gran banquete' o 'del matrimonio del hijo del rey'. Se trata de una parábola narrada por Jesús en el Nuevo Testamento, la podemos encontrar en Mateo y Lucas 14:15-24.

En este relato, se cuenta la historia de un rey que organizó un banquete al que invitó a mucha gente. Sus servidores fueron a avisar a los invitados, pero éstos no quisieron ir. Entonces el rey volvió a llamar, pero ellos no hicieron caso y se fueron a sus campos y negocios. Más tarde, el rey dijo a sus criados: "Id a decidle a todo el mundo e invitad a todos los que encontréis por el camino". Tanto buenos, malos, pobres y ricos asistieron al banquete del rey y, todos juntos, celebraron una gran fiesta. Los criados 
salieron y reunieron a todos los que encontraron, y la sala se llenó de invitados. Al entrar el rey para ver a los comensales, observó que uno de ellos no llevaba traje de fiesta. Entonces, el rey dijo a sus servidores: “Atadlo de pies y manos y echadlo fuera a las tinieblas; allí llorará y le rechinarán los dientes. Porque muchos son los llamados, pero pocos los escogidos" (Mt 22,3-14).

Con esta parábola, Jesús nos habla del banquete del reino de los cielos, es decir, del banquete final. Pero, como ese banquete es anticipado y preparado por el banquete eucarístico, la parábola nos puede servir para reflexionar sobre los destinatarios de la Eucaristía y sobre sus comportamientos.

Esta parábola se expondrá en el aula con las figuras de los protagonistas de la historia, realizados previamente por el docente. Dichas figuras se colocarán frente a los niños, que verán la secuencia del relato. Relatar una historia requiere leer previamente el cuento y utilizar los recursos necesarios para captar la atención de los niños. En definitiva, hacer nuestra la historia contagiando curiosidad.

Una vez terminada la historia, será importante explicar a los alumnos que esta parábola es la forma que tiene Jesús de explicar la Eucaristía, ya que se trata de una invitación suya para que vivamos con Él para siempre si adoptamos su mensaje. Para comprobar la comprensión del relato, se realizarán las siguientes preguntas:

- ¿Qué personajes aparecían en la parábola?

- ¿Cómo se sintió el rey cuando vió que la gente no quería asistir a la fiesta?

- ¿Asistió gente al banquete del rey?

- ¿Por qué muchos de los invitados rechazaban la invitación del rey?

- ¿Vosotros acudís a la fiesta del señor, la Eucaristía?

Para finalizar, mantendremos una conversación con los alumnos, en la que dejaremos que expresen sus pensamientos sobre la parábola. Además, deberán realizar un dibujo sobre lo que más les haya llamado la atención para, posteriormente, colgar sus creaciones en las paredes del aula. Actividades como ésta, además de transmitir el mensaje de Jesús, ayudan a fomentar las dotes artísticas de los alumnos.

\subsection{FASE INTERMEDIA}

\section{Sesión 2. El enchufe que nos conecta con Dios}

Para esta actividad cooperativa la profesora realizará, de manera manual, un enchufe y una clavija de juguete de grandes dimensiones. Tras explicarle el funcionamiento del juego, los alumnos deberán situarse de manera circular y cogerse de la mano. Esta posición representará la electricidad. La maestra, en todo momento, estará en el centro del círculo portando la clavija y le entregará el enchufe a uno de los niños. 
Cuando la clavija esté desenchufada, todos los niños permanecerán quietos, sin moverse, como si fueran estatuas. En cuanto la profesora conecte la clavija al enchufe, los alumnos se podrán mover simulando que a través de ellos se transmite corriente eléctrica, vida.

Cuando la profesora desconecte la clavija, los niños caerán al suelo y volverán a ser estatuas. Entonces la profesora, desde el espacio central, explicará a sus alumnos que los aparatos eléctricos como la lavadora o la tostadora no pueden funcionar si no tienen corriente.

Posteriormente, la docente formulará preguntas como las siguientes:

\footnotetext{
- Para ver dibujos en la televisión, se necesita electricidad, ¿no? Acto seguido, conectará la clavija y todos los niños volverán a cobrar vida.

- Y si no tenemos electricidad, ¿no podremos ver los dibujos? Tras esta cuestión, la maestra desconectará el enchufe y, por lo tanto, todos los niños volverán a escenificar su apagón.
}

Estas preguntas se repetirán varias veces, aludiendo a la variedad de objetos que existen. Seguidamente, la docente relacionará esta actividad con el tema central del proyecto: la Eucaristía. Les explicará a los alumnos que Jesús es nuestro contacto y nosotros simbolizamos los electrodomésticos. Entonces, si estamos unidos a Jesús, Él nos da vida. Y, al contrario, si no estamos en relación con Jesús, perderemos vitalidad.

Se pueden formular infinidad de frases. Por ejemplo, podemos relacionar el ir a la Iglesia con la inyección de electricidad (momento en el que volveríamos a enchufar la clavija).

Continuaremos el juego aludiendo a las distintas partes que componen el acto de una misa, por ejemplo: cuando se lee la palabra de Dios, cuando nos damos la paz o cuando se recibe la Comunión. También se pronunciarán actitudes negativas, como la distracción, los actos irresponsables o la ausencia en misa. De esta manera, la clavija se irá conectando y desconectando hasta que los alumnos interioricen la reflexión.

\subsection{FASE FINAL}

\section{$\underline{\text { Sesión 3. ¿ Quien quiere venir a mi fiesta }}$}

En esta sesión, la profesora realizará un gran mural presidido por la imagen de Jesús. Dicho mural se completará con una fiesta llena de siluetas de niños sin rostro. A los alumnos se les encomendará la tarea de traer al colegio una foto suya de carnet.Posteriormente, deberán pegar su foto en el rostro de las siluetas con la intención de inmortalizar su presencia en la fiesta de Dios.

Esta actividad podría ser extensible a todo el alumnado del colegio. Así, el mural podría representar y celebrar la gran diversidad presente en nuestras aulas. Incluso, dentro del personal docente, hemos pensado inaugurar este mural gigante con un multitudinario acto eucarístico, que incluya sus 
característicos cantos y rezos. De esta manera, los alumnos podrán visualizar el desarrollo de una Eucaristía.

\section{CONCLUSIÓN}

A modo de conclusión, vamos a comprobar si nuestra propuesta de intervención ha cumplido con los objetivos planteados inicialmente:

El objetivo general que pretendíamos con este proyecto era:

- Encontrar puntos de unión entre la Eucaristía y la clase de religión

A raíz del conjunto de actividades propuestas, consideramos que este objetivo siempre ha estado presente en nuestra metodología, que demuestra que la transmisión interactiva de la Eucaristía a través de las clases de religión es esencial para fomentar los valores cristianos en los niños.

Como maestros consideramos primordial que los niños no solo adquieran aprendizajes curriculares, también resultan importantes las enseñanzas basadas en su propio desarrollo personal como la empatía, el respeto, el amor, la cooperación y la bondad. Enseñanzas reflejadas en el acto fundamental de la Eucaristía, la consagración.

Para afrontar esta propuesta de intervención resulta muy importante la actitud del docente que, a través de su ingenio, creatividad, palabras, emociones y expresiones, debe contagiar la alegría que representa la gran fiesta del Señor, la Eucaristía, acercando la figura de Jesús a los más jóvenes.

Además de los ya comentados, uno de los puntos fundamentales que aporta esta propuesta es

la creación de un clima agradable en el aula cimentado sobre los valores cristianos, que aporte una mejora general del proceso de enseñanza.

En definitiva, el sentido de este proyecto puede resumirse con la siguiente frase de Jesús: "Dejen que los niños se acerquen a mí, no se lo impidan” (Mt 19,14). 


\section{BIBLIOGRAFÍA}

Aldazábal, J. (1999). La eucaristía. Centre de Pastoral Litúrgica. https://books.google.es/books?id=m7s7lbJV_4C\&lpg=PA9\&dq=partes\%20de\%20la\%20Eucarist\%C3\% $\mathrm{ADa} \& 1 \mathrm{r} \& \mathrm{hl}=\mathrm{es} \& \mathrm{pg}=\mathrm{PP} 1 \mathrm{H} \mathrm{v}=$ onepage $\& \mathrm{q}=$ partes $\% 20 \mathrm{de} \% 201 \mathrm{a} \% 20$ Eucarist $\% \mathrm{C} 3 \% \mathrm{ADa} \& \mathrm{f}=$ false

Asamblea General. (20 de noviembre de 1959). Declaración de los Derechos del Niño. https://observatoriodegenero.poder-judicial.go.cr/images/Normativa/Internacional/NinosNinas/Obsgenero-Normativa-Internacional-Declaracin-derechos-ninos-AG-res.pdf

Asamblea General de Naciones Unidas (25 de noviembre de 1981). Declaración sobre la eliminación de todas las formas de intolerancia y discriminación fundadas en la religión o en las convicciones.https://www.mpr.gob.es/mpr/subse/libertadreligiosa/Documents/Normativa_Internacional/ Declaracion25_1981_Universal.pdf

Baena Extremera, A., \& Ruiz Montero, P. J. (2016). El juego motor como actividad física organizada en la enseñanza y la recreación. EmásF: revista digital de educación física, (38), 73-86. https://dialnet.unirioja.es/servlet/articulo?codigo=5351993

Chamorro, I. L. (2010). El juego en la educación infantil y primaria. Autodidacta, 1(3), 19-37. http://educacioninicial.mx/wp-content/uploads/2017/11/JuegoEIP.pdf

Conferencia Episcopal Española. (2018). El profesor de Religión Católica: identidad y misión. https://www.conferenciaepiscopal.com.es/wp-

content/uploads/2018/07/1998_profesor_religion_catolica_identidad_y_mision.pdf

Cuéllar de Lucas, Y., Pérez-Brunicardi, D., \& De la Iglesia, M. (2015). Enseñanza cooperativa como instrumento para la inclusión de un niño con Trastorno de Espectro Autista (TEA) mediante juegos cooperativos en un aula de Educación Infantil. Revista Arbitrada del CIEG-Centro de Investigación Y Estudios Gerenciales, 21, 259-271. http://www.grupocieg.org/archivos_revista/Ed.\%2021\%20(259271)\%20Cu\%C3\%A91lar\%20de\%20Lucas\%20y\%20otros\%20-

$\% 20$ septiembre\%202015_articulo_id213.pdf

Fyler Town, George (1987). Las parábolas y convergencias, Columbia: Ether's. http://repositorio.udh.edu.pe/bitstream/handle/123456789/925/T_047_47121233-

T.pdf..pdf?sequence $=1 \&$ isAllowed $=y$

Gran Enciclopedia $\quad$ Planeta $\quad$ Saber. $\quad$ (s.f). $\quad$ Parábola. http://www.planetasaber.com/search/results.asp?txt=parabola

Infovaticana (8 de enero de 2014). Multiplicación de los panes y los peces. https://infovaticana.com/blogs/adelante-la-fe/evangelio-de-hoy-multiplicacion-de-panes-y-peces/

Jaqueira, A. R., Lavega Burgués, P., Lagardera Otero, F., Araujo, P., \& Rodrigues, M. (2013).

Educando para la paz jugando: género y emociones en la práctica de juegos cooperativos competitivos. https://revistas.um.es/educatio/article/download/194071/159431/

Marín-Díaz, V., \& Sánchez-Cuenca, C. (2015). Formación en valores y cuentos tradicionales en la etapa de educación infantil. Revista Latinoamericana de Ciencias Sociales, Niñez y 
Juventud, 13(2), 1093-1106. https://www.redalyc.org/pdf/773/77340728038.pdf

Martel, F. (2007). Las primeras imágenes de Dios en los niños. Proyección: Teología y mundo actual, (227), 309-323. https://dialnet.unirioja.es/servlet/articulo?codigo=2529801

Nuevo Testamento. (1990). El libro del pueblo de Dios.

https://www.vatican.va/archive/ESL0506/_INDEX.HTM

Ortiz Campos, L. M. (2019). El sacramento de la Eucaristía en el pensamiento de Santa Teresa del

Niño

Jesús.

http://repositorio.ucss.edu.pe/bitstream/handle/UCSS/674/Ortiz_Luz_tesis_bachiller_2019.pd

f? sequence $=1 \&$ isAllowed $=y$

Peña, A (2009). Los niños y la eucaristía. http://www.esclavasdelsantisimo.org/wpcontent/uploads/ninos_y_eucaristia.pdf

Real Academia Española. (s.f). Parábola. En Diccionario de la lengua española.

https://dle.rae.es/par\%C3\%A1bola

Sagrada Congregación para el Culto Divino. Directorio para las misas con niños. https://scholar.google.es/scholar?hl=es\&as_sdt=0\%2C5\&q=para+el+Culto+Divino\%2C+S.+ C.+PARA+LAS+MISAS+CON+NI\%C3\%91OS.\&btnG $=$

Söding, G. J. (2013). De la metáfora viva a las parábolas del Reino: Paul Ricoeur y el lenguaje creativo de Jesús. https://repositorio.uca.edu.ar/bitstream/123456789/4867/1/metafora-viva-parabolas-reinoricoeur.pdf

Taller de Misa con Niños (7 de febrero de 2015). La Misa es una Fiesta [Vídeo]. Youtube. https://www.youtube.com/watch?v=5BzOS_PPweI

Touriñán-López, J. M. (2006). La educación intercultural como ejercicio de educación en valores. https://dadun.unav.edu/bitstream/10171/8928/1/EA.PDF

Vaticano (1322). El Catecismo de la Iglesia católica. Librería Editrice Vaticana. https://www.vatican.va/archive/catechism_sp/p2s2c1a3_sp.html

Vaticano (1965). Presbyterorum ordinis. Librería Editrice Vaticana.

https://www.vatican.va/archive/hist_councils/ii_vatican_council/documents/vatii_decree_19651207_presbyterorum-ordinis_sp.html 